\title{
A Study on Emerging Management Practices of Renewable Energy Companies after the Outbreak of Covid-19: Using an Interpretive Structural Modeling (ISM) Approach
}

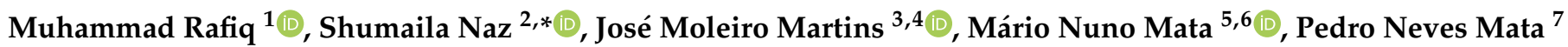 \\ and Saif Maqbool ${ }^{8}$ (D)
}

check for updates

Citation: Rafiq, M.; Naz, S.; Martins, J.M.; Mata, M.N.; Mata, P.N.; Maqbool, S. A Study on Emerging Management Practices of Renewable Energy Companies after the Outbreak of Covid-19: Using an Interpretive Structural Modeling (ISM) Approach. Sustainability 2021, 13, 3420. https://doi.org/10.3390/su13063420

Academic Editor: Chi Keung Marco Lau

Received: 22 January 2021

Accepted: 9 March 2021

Published: 19 March 2021

Publisher's Note: MDPI stays neutral with regard to jurisdictional claims in published maps and institutional affiliations.

Copyright: (c) 2021 by the authors. Licensee MDPI, Basel, Switzerland. This article is an open access article distributed under the terms and conditions of the Creative Commons Attribution (CC BY) license (https:/ / creativecommons.org/licenses/by/ $4.0 /)$.
1 Faculty of Management Sciences, Superior University, Lahore 54000, Pakistan; m.rafiq@ncepu.edu.cn

2 Faculty of Business Administration, Iqra University, Karachi 75500, Pakistan

3 Department of Management, The Lisbon Accounting and Business School (ISCAL), The Polytechnical Institute of Lisbon, 1069-035 Lisbon, Portugal; zdmmartins@gmail.com

4 Business Research Unit (BRU-IUL), Lisbon University Institute (ISCTE-IUL), 1649-026 Lisbon, Portugal

5 Department of Finance, Lisbon Accounting and Business School (ISCAL), The Polytechnical Institute of Lisbon, 1069-035 Lisbon, Portugal; mnmata@iscal.ipl.pt

6 Department of Management and Technology, Santarém Management School (ESGTS-IPS), Polytechnic Institute of Santarém, 2001-904 Santarém, Portugal

7 Department of Information Science and Technology, Information Sciences and Technologies and Architecture Research Center (ISTAR), Lisbon University Institute (ISCTE-IUL), 1649-026 Lisbon, Portugal; pmata@escs.ipl.pt

8 Department of Management, Chiniot-Faisalabad Campus, National University of Computer and Emerging Sciences, Islamabad 44000, Pakistan; saif.maqbool@nu.edu.pk

* Correspondence: shumaila.superior@gmail.com

Abstract: The role of management practices in the success of renewable energy organizations is not negligible because management practices are the backbone of any organization. Energy organizations are facing drastic environmental issues; therefore, the sector inevitably requires environment- friendly production, which is only possible through the deployment of concurrent management practices because sluggish management practices lead to dormancy and inadequate performance. This study investigates the emerging management practices that will enable the renewable energy sector to fulfill the current demands of the market, especially after the outbreak of the Covid-19 pandemic. This research deployed a qualitative research methodology that is grounded in the interpretivism research paradigm. Interpretive structural modeling (ISM) was applied due to the extent of its logical thinking, and its ability to address complex issues and disseminate results precisely. Data were collected through primary (structured and unstructured interviews) and secondary sources (literature reviews published in the last 10 years). Interviews of top- and middle-level managers working in the renewable energy sector of developing countries were conducted. The findings of the study postulate that the implementation of knowledge management practices and policy changes are the key influencing factors to achieve sustainable organizational performance. Decentralization also has the potential to influence and navigate the organizational performance of energy companies. The findings of the research advocate innovative practices for the energy sector that influence organizational performance. The qualitative findings of the study suggest that emerging practices, including knowledge management practices and decentralization, may proliferate organizational growth and development. The novel framework of the study implies that organizations should work progressively in deploying emerging management practices such as establishing a central response hub to avoid delays under the umbrella of resilience leadership.

Keywords: renewable energy; emerging management practices; knowledge management; decentralization; sustainable organizational performance 


\section{Introduction}

The current and rapidly changing competitive environment presents potential opportunities and threats for the renewable energy sector. Renewable energy is the strongest pillar of the energy system and has the potential to use emerging management practices [1]. These factors imply that organizations should adopt emerging management practices to respond competitively. The literature suggests that various management practices are utilized by different firms to increase their outcome and cope with changing market trends. Other organizations try to replicate these practices and resources to improve their productivity. According to Michael [2], for every organization, motivated and creative human capital is the only resource of the organization that cannot be imitated, replaced, or reproduced. An organization's crucial responsibility is to enhance customers' experience and society at large through existing human resources. Hamel [3] asserted that emerging management practices, which were initiated at the start of the 19th century, have reached their limit of improvement and a new paradigm is now necessary for the era of the 20th century to meet the challenges of an unpredictable world. After the outbreak of Covid-19, it became inevitable to address management issues for organizational growth. Large organizations change strategies by incorporating their organizational resources, which have been built over time.

After the pandemic, the entire structure of organizations changed, whether it is its internal structure or external working environment that needs new practices to handle organizational affairs efficiently. Emerging management practices do not require the transformation of the entire structure of the organization; rather, they require turning the lens toward the working procedures of firms. Organizations, especially innovative organizations, may not last unless they apply unique ways of operationalization according to their dynamics and structure, which is only possible through inculcating an efficient knowledge management process [4]. Therefore, it is important to analyze in depth how to implement emerging management practices, especially knowledge management and decentralization phenomena, to handle the challenges emerging during and after Covid-19 to improve sustainable organizational performance [5].

The literature on management practices [6-8] explores that while applying emerging management practices, a grounded and knowledge-based point of view is needed. Adhikari [9] suggested that all strategies and practices must be accompanied by knowledge management to gain a competitive advantage in the modern corporate world. To compete with ever-changing situations around the globe, companies noticed that knowledge in an organization is continuing asset. According to Hustedt, Bohl [10] it has now been accepted by organizations that knowledge is the true source of power and will increasingly become so as the 21st century progresses. Natek and Zwilling [11] reported that the corporate world is considering knowledge management processes-acquisition, dissemination, and implementation - as a foundation of its processes. The tentative support of decentralization in organizational growth across sectors is widely noted and discussed by different researchers [12-14]. The impact of decentralization triggers increased motivation, sense of ownership, increased employee productivity, and return of net assets, etc. According to Deliotte [15], many innovative organizational practices emerged in response to Covid-19, such as the central response office, partnering with stakeholders, blended learning with a new focus, and, ultimately, by shifting operations to digital mechanisms. Additionally, leadership readiness to accept change, which consequently leads to the invention of management practices, is important for organizational growth [16].

The situation in developing countries during the pandemic is worse, and organizations are striving to seek emerging practices to survive and grow. The renewable energy sector in developing countries is gearing up, and companies are heavily investing in this sector due to the high demand for renewable energy. Hence, this research attempts to explore the challenging problems of the energy sector in emerging economies and contribute theoretically by adding new literature on (1) emerging management practices (2) decentralization and (3) knowledge management, with its application in the current setup of the renewable 
energy sector. The research also delivers the insight of a "knowledge-based perspective" that suggests that policymakers design policies according to modern requirements of the current era. Pakistan is the sixth-largest populous country, with an integral geographical location on the continent of Asia. It requires sufficient energy resources to meet its industrial, commercial, and household demands to keep its growth and development. The potential of renewable energy in Pakistan is above 50,000 MW. The installed capacity of renewable energy during the fiscal year 2019-2020 increased by $6 \%$ as compared to the previous year. This indicates that developing countries are heading quickly towards renewable energy production and consumption. The renewable energy sector, especially solar, is growing exponentially, but meanwhile faces a different problem concerning durability [17]. This is because the demand for neat and clean energy is increasing over time [18]. The total electricity generation capacity of Pakistan has reached 35,972 MW. The contribution of renewable energy, including wind, solar and hydel, is approximately $8 \%$ in total generation capacity. However, as a matter of fact, despite being bestowed with abundant resources and enormous ways of energy generation potential, the country is unable to meet its energy demands and is facing an acute energy shortfall $[19,20]$. Hence, this study contributes uniquely by addressing energy issues in developing countries, specifically in Pakistan, and its findings should be reasonably prolific for practitioners and policymakers in renewable energy companies in developing countries.

\section{Literature Review}

For business survival during the uncertainty brought by Covid-19, firms have been forced to develop new management practices that are accessible and suitable for the current era. A conscious path of transformation in operations is much needed to help organizations minimize the critically alarming and ongoing effects of Covid-19 that have been unfavorable for people, operations, and overall business activities, especially in the energy sector.

\subsection{Knowledge Management}

Following Rubenstein-Montano, Liebowitz [21], knowledge has been observed widely in Western philosophy due to its significant contribution in strategic decision making since the classical Greek era. More recently, scholars proclaimed that for effective strategic actions, organizations may increase their capacity through knowledge management [22,23]. Moreover, they asserted that knowledge can be viewed in variant forms such as the capacity of acquiring knowledge, access to information, state of mind, and ways to process the information. Handling knowledge has become an emerging tool and asset for organizations in recent years. Researchers have developed a comprehensive knowledge management system (KMS) through individual knowledge management and organizational knowledge. A resource-based view (RBV) laid down the foundation for these concepts, where firms develop a proper KMS process as initially presented by Penrose 1959 and extended by $[22,24,25]$. Tacit and explicit streams of knowledge were defined by Natek and Zwilling [11] as essential for knowledge acquisition. Furthermore, an emotionally intelligent organization also leads to knowledge-sharing behavior [26]. Tacit knowledge comprises technical and thinking elements that are exposed through actions, experiences, and specific backgrounds. It comes under the classification of "cognitive" knowledge: consisting of viewpoints, paradigms, beliefs, and mental maps. López-Nicolás and Meroño-Cerdán [27] suggested that the creativity of any organization can be enhanced through tacit knowledge, while explicit knowledge can be enriched through informal ways of acquiring information. To understand and develop action-oriented strategies for an organization, it is better to first understand the available organizational sources of knowledge. 


\subsection{Decentralization}

Decentralization is a necessary practice to be implemented as the main integral element for any organization, especially during the initial growth phase. Decentralization is characterized as empowering your subordinates to take decisions on their own to save time and to avoid delays of decisions. This concept has achieved success in the developed world but is less realized in the developing world. Therefore, the objective of this study is to explore decentralization as an emerging practice that can have an impact at the corporate level in developing countries [28,29]. It is also argued that the implications of implementing decentralization include the complexity of the process and ambiguity in the roles of employees at a higher level [30]. This phenomenon is still misunderstood because of prevailing ambiguity about its mechanisms and strategies. The contextual setting of the country is the main factor that contributes to the process of decentralization [31,32]. Universally, it is agreed that the criteria of decentralization are complex and its measuring tools are scarce. The power and its delegation are complex phenomena due to its susceptible measurable categories and substantial attachment to positions. The measuring criteria of the decentralized institution should be different from that for those that are highly centralized. According to Vengroff and Salem [33] in any country, the relative quality of decentralization (D) is measured through the criteria of

$$
\mathrm{D}=\mathrm{f}(\mathrm{S}, \mathrm{I}, \mathrm{C})
$$

where " $\mathrm{S}$ " denotes the function of range; " $\mathrm{I}$ " represents the intensity and " $\mathrm{C}$ " represents a commitment. Additionally, they asserted that decentralization is influenced by the opportunities available to participants, geographical area, population, and substantial power scheme. Decentralization is known best for accountability, democratization, selfempowerment, reducing conflict, and providing civic responsibility [34].

\subsection{Emerging Management Practices}

Emerging management practices are an ever-evolving notion and continue to change according to contextual factors. The operations of organizations dramatically changed after the appearance of Covid-19. Companies with a flexible working environment, rather than those companies that are rigid and reluctant to adopt new management practices, showed their sustainability. The debate about emerging management practices, specifically after the pandemic, is multifaceted and yet has not reached a final conclusion. It is estimated that the GDP of developed economies will fall to $6 \%$ and developing economies may face negative growth. Covid-19 is not only a health dilemma but also signifies an economic crisis that will lead to the sluggish performance of organizations and ultimately to unemployment and poverty [35]. Karmaker, Ahmed [35] emphasized that strategies like collaboration with one's stakeholders and making them partners in business affairs are the emerging trends during this challenging period. Additionally, they proclaimed that sustainable supply chain procurement is becoming more common because standalone organizations cannot survive. Deliotte [15] advocated the philosophy of respond, recover, and thrive (RRT) as an immediate remedy to sluggish performance. Resilience leadership can inspire employees to help them to lead in difficult and unexpected days. Such leadership ensures that all key stakeholders are critical contributors, and their health and safety concerns are put forward as a priority. Before the pandemic, customized and delegated services were encouraged; however, keeping in mind the present dilemma, responding centrally to the designated problem by seeking endorsements across all departments it is now highly valued. Based on a careful investigation, the following concepts are derived from the literature. The key issues are identified through the literature and are depicted in Table 1 below. 
Table 1. Identification of key issues through systematic review.

\begin{tabular}{ccc}
\hline Serial \# & Key Issues/Factors & References \\
\hline 1 & Understanding knowledge management $(\mathrm{KM})$ narrative & {$[4,8,11,22,36]$} \\
2 & Emerging Management practices & {$[3,15,19,35]$} \\
3 & Decentralization mechanisms & {$[12,14,30,32,34]$} \\
4 & Effect of Decentralization on owner's control & {$[10,12,13,29]$} \\
5 & Implementation of KM and policy change & {$[9,15,21,24,27,35]$} \\
\hline
\end{tabular}

\subsection{Knowledge-Based Perspective as a Theoretical Lens}

Penrose [37] proposed a resource-based theory that focused on rare, inimitable, valuable, and trustworthy resources as a foundation for any organization that is needed for sustaining long-term growth. Later on, this approach was highly admired, laid the foundation for a knowledge-based perspective, and cited [24,38,39]. The knowledge-based perspective indicates that tangible resources can yield results only if they are aligned and coherent with each other. Completing this process of aligning tangible resources depends on to what extent the firm is knowledgeable. The acquisition and retention of knowledge heavily rely on culture, policies, strategic systems, routines, and documents $[7,8,22,40]$. Nevertheless, individual characteristics are also important triggers. Thus, KMS is the best strategy to use to apply decentralization concepts organization-wide. In aggressive competition, knowledge management is used as a weapon for sustainable development to compete and grow [41]. Additionally, sustainable organizational performance can be increased through proper mechanisms of storing, retrieving, and using a firm's knowledge. On the whole, organizational processes and performances can be increased through knowledge. Due to its multiple facets and heterogeneity, it is confirmed that KMS can be applied in the energy sector particularly. Thus, this study attempts to explore the KMS mechanisms in renewable energy companies. The variable identification through literature is shown in Table 2.

Table 2. Interpretive structural modeling (ISM) reference table; variable identification.

\begin{tabular}{clll}
\hline Serial \# & \multicolumn{1}{c}{ Key Issues/Factors } & Variables & \multicolumn{1}{c}{ References } \\
\hline 1 & Understanding KM narrative & V1 & {$[4,8,11,22,36]$} \\
2 & Emerging management practices & V2 & {$[3,15,19,35]$} \\
3 & Decentralization mechanisms & V3 & {$[12,14,30,32,34]$} \\
4 & Effect of Decentralization on owner's control & V4 & {$[10,12,13,29]$} \\
5 & Implementation of KM and policy change & V5 & {$[9,15,21,24,27,35]$} \\
\hline
\end{tabular}

\section{Methods, Materials, and Research Tools}

Since the objective of the study was to explore emerging management practices indepth in renewable energy companies hence, a qualitative methodology was considered most suitable and appropriate in this context. The qualitative approach was deployed in the research by using interpretive structural modeling, hereafter referred to as "ISM". ISM is more appropriate when the description and exploration are required through interviews and literature. ISM is more advantageous than other techniques because it helps to draw the research model of the study. Although ISM has been used for a couple of decades, it is still among the most widely used research techniques in qualitative research design. Lee, Saunders [42] indicated that quicker and real experiences can only be measured through qualitative research methodology. The answer to the untapped and unexplored phenomenon of emerging management practices is not possible through any customary tool except collecting data through interviewing and observing managers who are working in the system, especially in the context of developing countries. For a deeper understanding of the phenomena, a subjective approach to understand a reality where little information is known is considered the best approach [43]. This study used a systematic literature review for the initial concept and variable identification. Later, these concepts are authorized 
by experts and practitioners from the renewable energy sector. ISM is a more helpful modeling technique that is used as a tool for logical thinking, approaching complex issues carefully, and then disseminating the results to others [44,45]. The ISM process consists of the following (1) Identification of key issues/variables such as the contribution of emerging management practices, $\mathrm{KM}$, and decentralization toward sustainable organizational performance. (2) Identification of relationships between variables using the structural self-interaction matrix, hereafter denoted as "SSIM". (3) Developing a reachability matrix by converting the SSIM. (4) Testing transitivity in the next step. (5) Deriving model levels using the reachability matrix. (6) Translating the relationship and drawing an ISM model. (7) Reviewing the inconsistencies and revising accordingly. The structural flow is depicted in Figure 1.

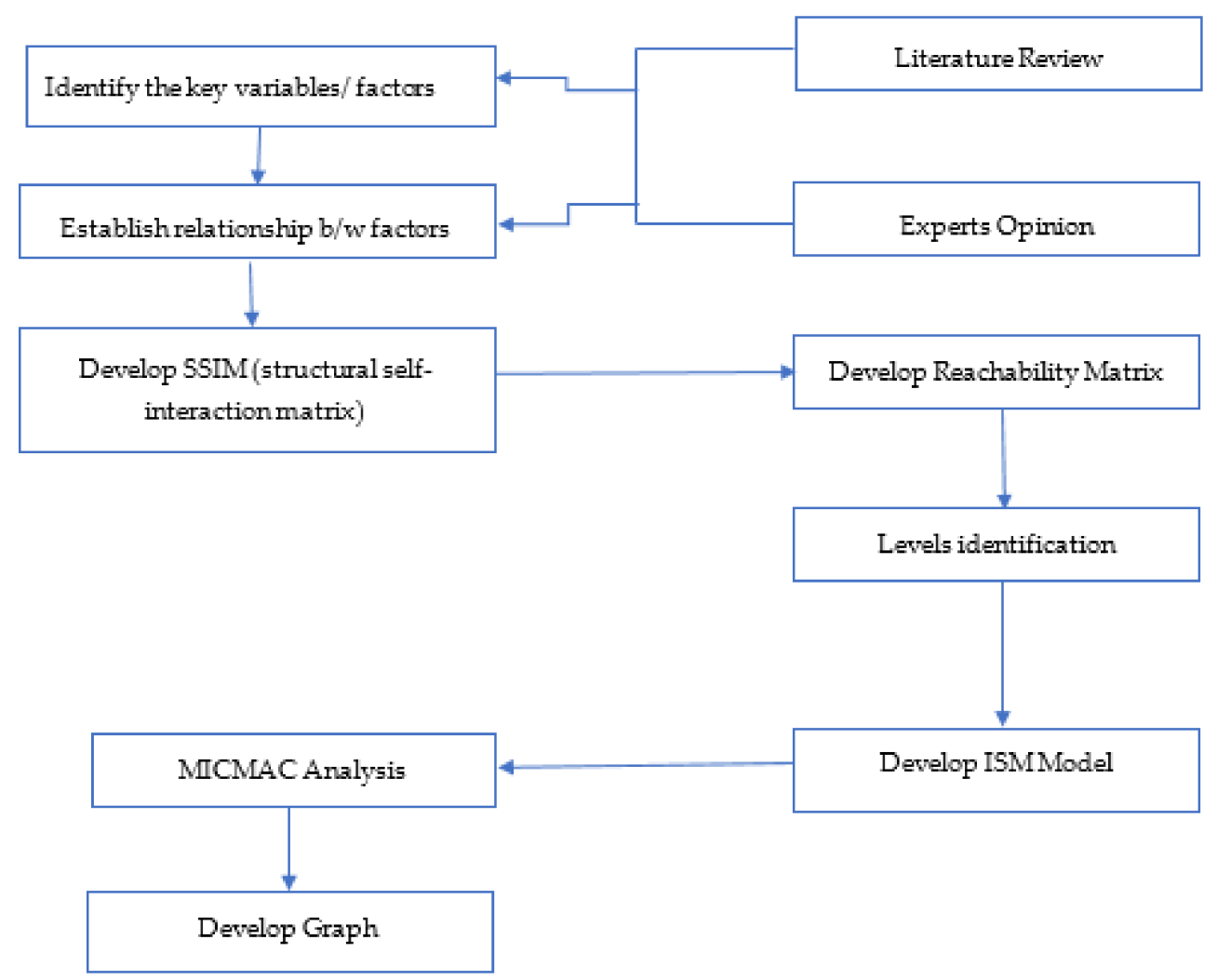

Figure 1. Structural Flow of ISM.

\subsection{Data Collection}

The data in this study was gathered through primary and secondary sources. For primary sources, top- and middle-level managers with a minimum of two years of experience and substantial information about the variables of the study were recruited. The interview questions along with the consent form were delivered to them before the interview so they were better informed about the concepts. In the secondary form of data, the information was collected through rigorous literature related to the topic. Both forms of data helped to finalize the variables of the study.

\subsection{Sampling Strategy}

Aligned to the qualitative research paradigm used for this study, a non-probability sampling strategy was used. It is suggested by Sadler, Lee [46] that when the population is narrowly defined, a snowball sampling strategy is the best strategy to reach the targeted population. Snowball sampling involves a researcher reaching a successor respondent through a chosen respondent. Hence, this study used a snowball sampling strategy where 
potential respondents were recruited with the help of existing respondents. A total of 13 respondents was recruited to obtain their responses on the research topic.

\subsection{Findings}

\subsubsection{Demographic}

The demographic profile of respondents depicts the role of women in the renewable energy sector because women's participation is minimal in developing countries. Hence, gender participation, along with other demographic factors including age and experience, are shown in the demographic section (Table 3).

Table 3. Demographics.

\begin{tabular}{cccc}
\hline Participants & Sex & Experience & Age \\
\hline P1 & M & 4 & $40-49$ \\
P2 & M & 13 & $20-29$ \\
P3 & M & 5 & $30-39$ \\
P4 & M & 3 & $30-39$ \\
P5 & F & 4 & $20-29$ \\
P6 & M & 4 & $20-29$ \\
P7 & F & 7 & $30-39$ \\
P8 & F & 3 & $20-29$ \\
P9 & M & 2 & $20-29$ \\
P10 & F & 4 & $30-39$ \\
P11 & M & 8 & $30-39$ \\
P12 & F & 3 & $30-39$ \\
P13 & & 7 & $30-39$ \\
\hline
\end{tabular}

Table 3 denotes that $62 \%$ of the total sample were male participants while $38 \%$ of participants in the study were female. In terms of age, $54 \%$ of participants were $30-39$ years old while $38 \%$ were $29-30$ years old, the second dominant age bracket. The study also indicates the education level of participants because education is the most important element for participants of this study. Of all participants, $69 \%$ had a master's degree while $3 \%$ had postgraduate degrees and $2 \%$ received a graduate degree. In total, $90 \%$ of companies selected for data collection were international, while only $10 \%$ percent of the sample were local companies.

ISM methodology provides that the structural self-interaction matrix (SSIM) is developed on the element set and the contextual relation based on a pairwise comparison of variables. These are developed through the opinions of experts and academicians as this is the best way to examine the relationship between variables, which ultimately strengthens the objective(s) of the study. The factors of knowledge management and decentralization, on the entire list, are embedding factors towards organizational success. The background and literature for these factors were explained to the experts, and the experts were asked to consider the adequacy of the concepts. Using Table 4, the SSIM matrix was designed as follows.

The next process was to convert the SSIM into a reachability matrix (RM). In this process, the matrix was converted into binary codes $(1,0)$. V, A, X, and $\mathrm{O}$ were replaced by 1 and 0 according to the VAXO rule. The following rules were applied in the process to derive a reachability matrix, as shown in Table 5.

- Where $i$ and $j$ in SSIM is " $V$ ", then insert the value of $i$ and $j$ as " 1 " and then $j$ and $i$ as " 0 " in the reachability matrix.

- Where $i$ and $j$ in SSIM is " $A$ ", then insert the value of $i$ and $j$ as " 0 " and then $j$ and $i$ as " 1 " in the reachability matrix.

- Where $i$ and $j$ in SSIM is " $X$ ", then insert the value of $i$ and $j$ as " 1 " and then $j$ and $i$ as " 1 " in the reachability matrix.

- Where $i$ and $j$ in SSIM is " $O$ ", then insert the value of $i$ and $j$ as " 0 " and then $j$ and $i$ as " 0 " in the reachability matrix. 
Table 4. Structural self-interaction matrix (SSIM) matrix.

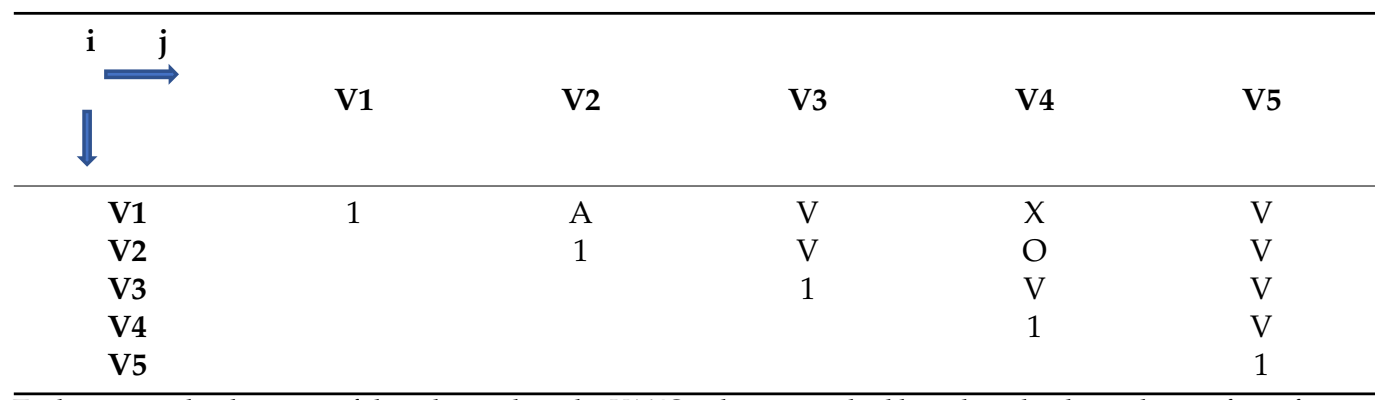

To determine the direction of the relationship, the VAXO rule was applied based on the dependence of two factors, $i$ and j. For making SSIM Table 4 possibilities were considered. Figure 2 provides further details.

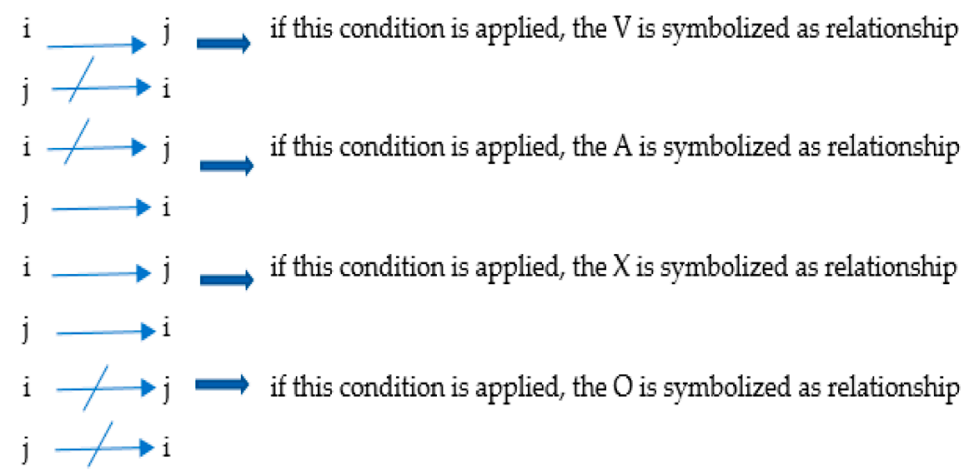

Figure 2. Explanations for the applied conditions.

Table 5. Reachability matrix.

\begin{tabular}{ccccccc}
\hline & V1 & V2 & V3 & V4 & V5 & Driving Variables \\
\hline V1 & & & & & & \\
V2 & 1 & 0 & 1 & 1 & 1 & 4 \\
V3 & 1 & 1 & 1 & 0 & 1 & 3 \\
V4 & 0 & 0 & 1 & 1 & 1 & 3 \\
V5 & 1 & 0 & 0 & 1 & 1 & 1 \\
Dependent Variables & 0 & 0 & 0 & 0 & 1 & 15 \\
\hline
\end{tabular}

The next step was to develop a transitivity set and the identification of levels. In this process, intersections and reachability columns were matched; the best matching was identified as level 1 and holds the top level in the hierarchy, and so on. In this case, V5 (sustainable organizational performance) was the first level for the ISM framework. After this process, V5 was removed in the next iteration in both columns, and we could reach the next level until the level of each factor was obtained. Table 6 indicates the level identification for each set.

The structural framework was drawn from the reachability matrix and intersection set. The $i$ to $j$ criteria of the relationship was demonstrated in the ISM framework in Figure 3. This Figure indicates that the implication of KM and policy change V2 had great significance for sustainable organizational performance, as it occupied the basic level of the ISM hierarchy. Sustainable organizational performance V5 was the influence factor on which emerging management practices depend, as it appeared at the top level of the ISM framework. The complete framework is shown in Figure 3. 
Table 6. Level identification.

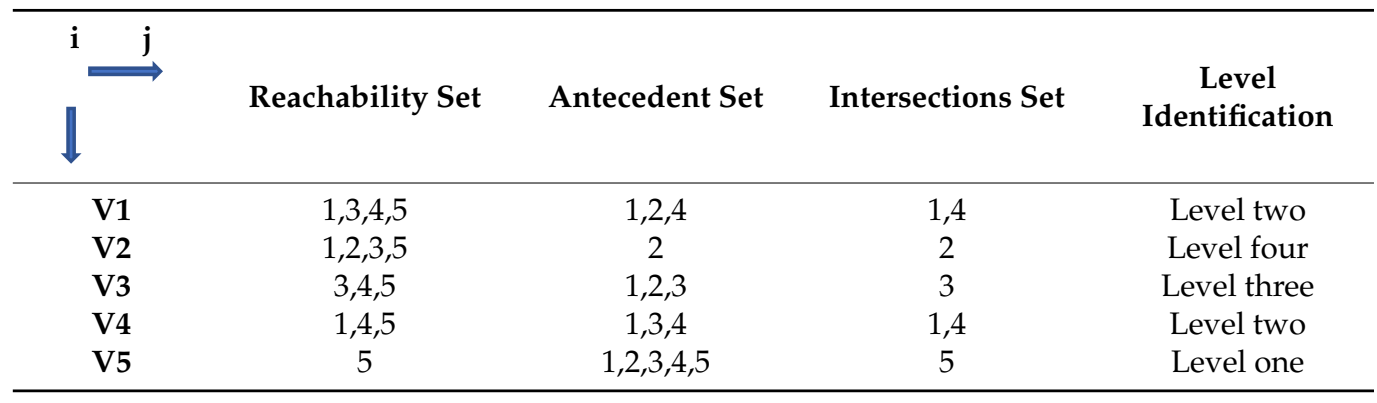

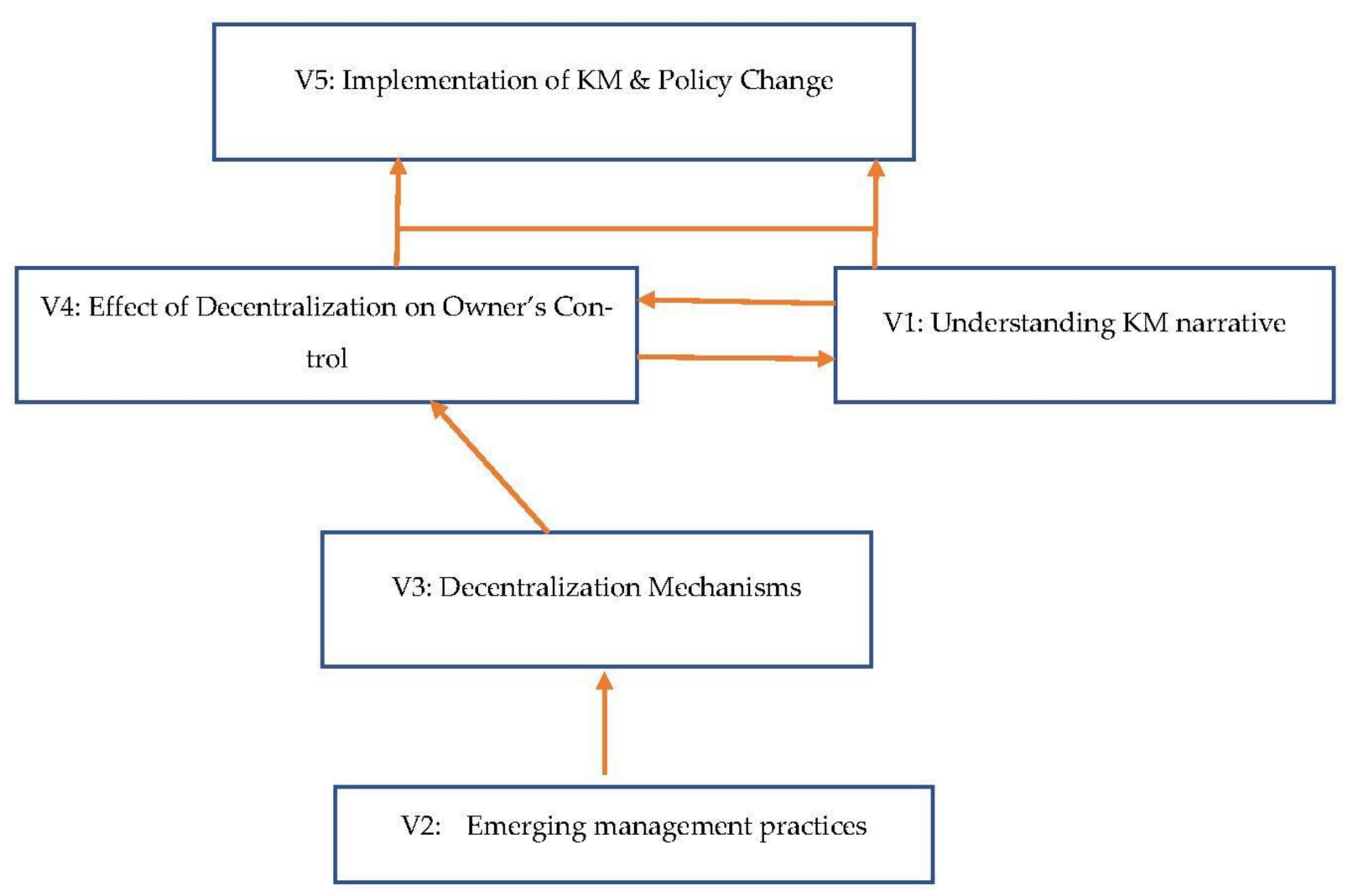

Figure 3. ISM framework.

\subsubsection{MICMAC Analysis}

"Matriced' Impacts Croisés Multiplication Appliquée á un Classement" also known as, "cross-impact matrix multiplication applied to classification", is abbreviated as MICMAC. The basic objective of utilizing MICMAC analysis is underpinned in analyzing the dependence power and drive power of factors. The principle of MICMAC is derived through the multiplication properties of matrices and it is performed to identify the key factors that drive a system in various categories. Based on their drive power and dependence power, the factors were classified into four categories, i.e., autonomous factors, linkage factors, dependent, and independent factors. Hence, the MICMAC analysis was utilized to classify the barriers. For classification, a cross-impact matrix was applied in MICMAC. It has two powers: (1) driving power on the vertical axis and (2) dependent power on $X$-axis. This analysis was further divided into four main categories: autonomous, linkage, independent or driving, and dependent factors [47]. Table 7 and Figure 4 depict the MICMAC analysis of the study. 
1. Figure 4 shows that none of the variables falls in the "autonomous" cluster, which indicates a weak driving and ultimately dependent power.

2. Variable two, "implementation of KM and policy change", falls in the independent or driving cluster. This indicates that this variable can lead other variables. Furthermore, it also has an indication that organizations need to critically focus on this factor.

3. In this study, three variables (V1, V3, and V4) lie in cluster three, named the "linking" cluster. It shows that these variables have a strong bonding with other variables, especially with the dependent variable. It can be assumed that it is vital to focus on these variables for sustainable operations of the organization.

4. Variable five falls in cluster four, named the "dependent' cluster". It shows that this variable is influenced by all other variables and is sensitive. Any change in other variables will have a greater impact on this variable.

Table 7. Dependent and driving variables for the cross-impact matrix multiplication applied to classification (MICMAC) analysis.

\begin{tabular}{cccc}
\hline Factors & Variables & $\begin{array}{c}\text { Driving } \\
\text { Variables }\end{array}$ & $\begin{array}{c}\text { Dependent } \\
\text { Variables }\end{array}$ \\
\hline Understanding the KM narrative & $\mathrm{V} 1$ & 4 & 3 \\
Emerging management practices & $\mathrm{V} 2$ & 4 & 1 \\
Decentralization mechanisms & $\mathrm{V} 3$ & 3 & 3 \\
Effect of decentralization on owner's control & $\mathrm{V} 4$ & 3 & 3 \\
Implementation of KM and policy change & $\mathrm{V} 5$ & 1 & 5 \\
\hline
\end{tabular}

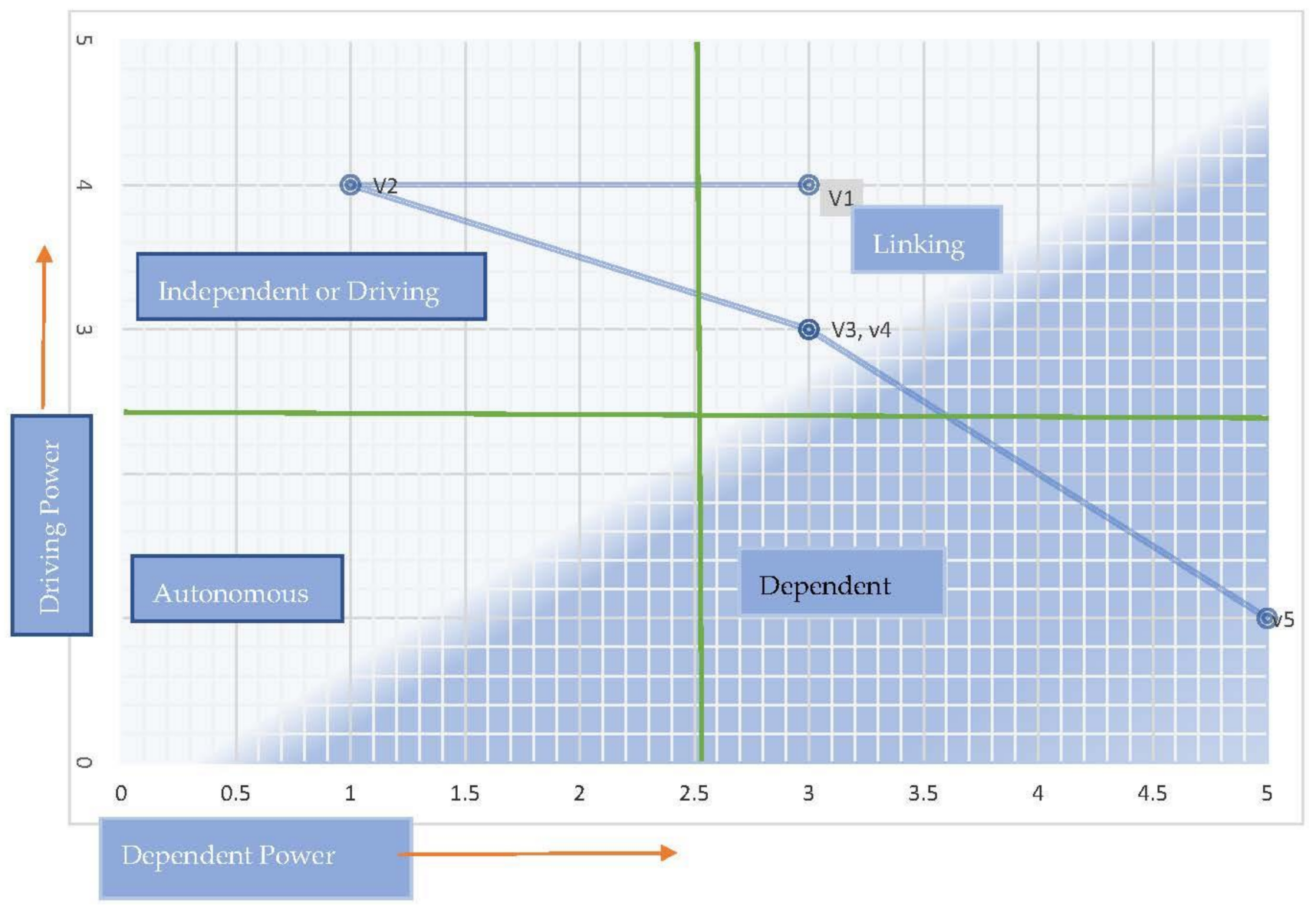

Figure 4. MICMAC analysis of the study. 


\section{Discussion}

The research findings indicate that knowledge management, central response control, resilience leadership, and decentralization are diluted in the basic operations of energy organizations especially after the emergence of Covid-19, and such practices are also found in recent studies [15]. The results of the study indicate that emerging management practices such as resilience leadership and a central response center are the baseline to implement the concepts of knowledge management and decentralization. Similar ideas have also been provided by different researchers in the past: namely, decentralization (John and Chathukulam [30]) and emerging management $[4,15,36,48]$ are weak in the energy sector of developing countries. However, in many cases, the companies are aware of the importance of these subjects. Moreover, the analysis of the interviews suggests that top management of organizations are willing to work on emerging management practices, because this concept is fundamental to organizational growth and innovation, but are unable to thoroughly work on them due to certain restraints. The analysis also shows that organizations are unaware of the rewards of these concepts in many cases. The participants of the study demonstrated their readiness to implement these concepts, provided that the institution provides them full support, resources, orientation, and training about emerging management practices, KMS, and decentralization mechanisms.

Emerging management practices are fundamental and are extremely necessary to firms' effectiveness and efficiency. The notion of knowledge is underpinned in the novel practices of management, and the importance of knowledge is also discussed in the previous literature $[8,23]$. The study reveals that capacity enhancement of an organization is possible through the implementation of knowledge management, which will ultimately lead to strategic actions and organizational competitiveness [23]. The findings of Santoro, Vrontis [22] also support the results of the study regarding the implementation of knowledge management: that it makes an organization unique, creative, and different from other organizations The evidence in Figure 3 indicates that the "implication of knowledge management and policy" is a dependent factor and is influenced by management practices. The MICMAC analysis of the study indicates that KM and policy change lie in the independent quadrant of the graph. Hence, these factors deeply influence organizational practices. The KM practices are mutually agreed by all respondents, but its understanding and implementation processes are applied differently: government support, organizational support, financial resources, time, and interest of the owner are the main barriers to the application of these practices. In the development of emerging management practices, KM strategies and policies are supported assertively as key drivers.

In developing countries, the debate about decentralization for empowerment and better decision making is attracting the interest of researchers and practitioners. However, there is a dearth of methods, and these need more attention for the effective handling of organizational affairs. The findings of Çakın [34] are also aligned with the results of this research. This study also found that top management is curious about the application of the decentralization phenomenon. The tools discovered by Rondinelli, Nellis [49] are fundamental for efficient deployment resources. The findings of this study are diverse and purely support the decentralization without affecting the control of the owner on the organizational process; they are meant to empower people such that they feel ownership in their organization by ensuring their participation in decision making through the cascading approach of management by objective (MBO). The participants, at large, recommended a down-streaming of power, which enhances this sense of responsibility. However, this study reveals that this practice is more appropriate for medium and large organizations rather than small enterprises. The MICMAC analysis of this study asserts that decentralization is a linking variable that is associated with other variables of the study, such as knowledge management and emerging management practices. The ISM model of the study depicts that decentralization is influenced by KM practices and emerging management practices. 


\section{Conclusions}

In conclusion, the ISM framework indicates that emerging management practices are the foundation for all other management practices in the renewable energy sector. Additionally, these are considered a driving factor that leads other business functions, which is concluded from the MICMAC analysis. Knowledge management and decentralization are considered indispensable tools of emerging management practices for the growth of the energy sector. Additionally, decentralization should also be considered important to increase the knowledge pool that eventually contributes to new ideas and their implementation. Furthermore, it is asserted that handling a large number of employees is mainly possible through decentralization practices, especially in the case of the energy sector. The energy sector is struggling with low financial resources that can be enriched through employer and employee coordination; by employing all these factors after consolidating them in the energy sector, the sector can grow exponentially in the long run.

\section{Implications}

The study is evocative in numerous ways after Covid-19, particularly for renewable energy companies. The duration of the pandemic provided many triggers for transforming management systems to deal with uncertain situations that may evolve in the future, and it is advocated that the application of emerging management practices has the potential to increase organizational management capacity in a turbulent and dynamic environment. Therefore, this study suggests establishing central response mechanisms supervised by resilience leadership who believe in innovative management practices, and applying them according to the contextual formation. The main objective of the study was to explore emerging management practices that can help energy organizations work efficiently during the pandemic and eventually after the pandemic situation. Mainly, the implications are segregated into two parts: (1) theoretical implications and (2) practical implications.

\subsection{Theoretical Implications}

There is a dearth of literature on emerging management practices and it is evolving over time. The importance of the current and updated literature during the crisis is increasing. The scarcity of literature mainly in the context of developing countries on emerging management practices is noted. Hence, this study is an important part of the literature that will help future researchers and academicians to describe and utilize the concepts for a better understanding of the phenomena. Additionally, the available literature was disjointed and confusing concerning understanding the concept of emerging management practices for renewable energy companies. Hence, this study has systematically gathered the literature and added current and contextual knowledge for a better understanding of the implications of the concept.

\subsection{Practical Implications}

The findings of the study are very useful for managers and policymakers to devise strategies that are helpful during emergencies and situations like Covid-19. Those strategies include developing a central response unit and flexible leadership policies. The findings of the study also help policymakers use emerging management practices as a foundation that triggers other factors, such as decentralization and knowledge management. Organizations must work on their knowledge management systems to innovate and compete during the pandemic.

\section{Limitations and Future Directions}

Like all research, this study also has a few limitations that need consideration for future research. The first limitation of the study is related to methodology; the qualitative research methodology has limited capacity to generalize phenomena to a larger context. Thus, future researchers can extend the extant study by using a mixed method for better exploration and generalization of the concept. Furthermore, statistical analysis should 
also be used for model testing. Another limitation of the study involves the sample size: the narrow sample of the study affects the generalizability of the concept such that in the future, the sample size of the study should be increased to obtain the desired data. It would also be beneficial to gather data from all levels rather than from only top and middle levels of management.

Author Contributions: Conceptualization, M.R.; data curation, J.M.M.; investigation, P.N.M.; methodology, S.N.; resources, M.N.M.; supervision, S.M.; validation, S.N.; writing-original draft, M.R. All authors have read and agreed to the published version of the manuscript.

Funding: This research received no external funding.

Institutional Review Board Statement: The study was conducted according to the guidelines of the Declaration of Helsinki. The review board of the Iqra University exempted the research for ethical approval, as it was a survey-based study. Top and middle-level managers working in the renewable energy sector gave consent on the telephone for conducting a questionnaire and participants of study filled questionnaires willingly.

Informed Consent Statement: Informed consent was obtained from all subjects involved in the study.

Data Availability Statement: The original data is provided by all the authors. If there are relevant research needs, the data can be obtained by sending an email to the corresponding author. Please indicate the purpose of the research and the statement of data confidentiality in the email.

Conflicts of Interest: This study has no conflict of interest.

Ethical Statement: The study is in compliance with APA (American Psychological Association) and is following all research ethical conducts. The data collection was done with their due consent and their names were kept anonymous during the study. They were informed about the purpose of the study before any kind of data collection procedure.

\section{References}

1. Čeryová, D.; Bullová, T.; Turčeková, N.; Adamičková, I.; Moravčíková, D.; Bielik, P. Assessment of the Renewable Energy Sector Performance Using Selected Indicators in European Union Countries. Resources 2020, 9, 102. [CrossRef]

2. Michael, A. A Handbook of Human Resource Management Practice; Kogan Page Business Books: London, UK, 2019.

3. Hamel, G. The future for strategy: An interview with Gary Hamel. Eur. Manag. J. 1993, 11, 150-157. [CrossRef]

4. Verma, S.; Gustafsson, A. Investigating the emerging COVID-19 research trends in the field of business and management: A bibliometric analysis approach. J. Bus. Res. 2020, 118, 253-261. [CrossRef] [PubMed]

5. Rafiq, M.; Zhang, X.; Yuan, J.; Naz, S.; Maqbool, S. Impact of a balanced scorecard as a strategic management system tool to improve sustainable development: Measuring the mediation of organizational performance through PLS-smart. Sustainability 2020, 12, 1365. [CrossRef]

6. Brecht, J.K.; Sargent, S.A.; Kader, A.A.; Mitcham, E.J.; Maul, F.; Brecht, P.E.; Menocal, O. Mango Postharvest Best Management Practices Manual. EDIS 2020, 2020. [CrossRef]

7. Chai, D.S.; Song, J.H.; You, Y.M. Psychological Ownership and Openness to Change: The Mediating Effects of Work Engagement, and Knowledge Creation. Perform. Improv. Q. 2020, 33, 305-326. [CrossRef]

8. Spender, J.C.; Grant, R.M. Knowledge and the firm: Overview. Strat. Manag. J. 1996, 17, 5-9. [CrossRef]

9. Adhikari, D.R. Knowledge management in academic institutions. Int. J. Educ. Manag. 2010, 24, 94-104. [CrossRef]

10. Hustedt, J.W.; Bohl, D.D.; Champagne, L. The detrimental effect of decentralization in digital replantation in the United States: 15 years of evidence from the national inpatient sample. J. Hand Surg. 2016, 41, 593-601. [CrossRef] [PubMed]

11. Natek, S.; Zwilling, M. Knowledge management systems support SECI model of knowledge-creating process. In Proceedings of the Joint International Conference, Technology, Innovation and Industrial Management, Timisoara, Romania, 25-27 May 2016; pp. 1123-1131.

12. Sadun, R.; Aghion, P.; Bloom, N.; Lucking, B.; Van Reenen, J. Turbulence, Firm Decentralization and Growth in Bad Times; National Bureau of Economic Research: Cambridge, MA, USA, 2017.

13. Bossert, T. Analyzing the decentralization of health systems in developing countries: Decision space, innovation and performance. Soc. Sci. Med. 1998, 47, 1513-1527. [CrossRef]

14. Zou, X.; Lei, C.; Gao, K.; Hu, C. Impact of Environmental Decentralization on Regional Green Development. J. Environ. Dev. 2019, 28, 412-441. [CrossRef]

15. Deloitte. Combating COVID-19 with an Agile Change Management Approach; A Guide for Organizations to Priorities People's Needs while mAintaining Business Continuity during Uncertain Times. India Perspective. Economic Times, IMF Report. 2020. 
16. Rafiq, M.; Haris, M.; Anwar, M.J.; Majeed, K.B. The impact of leadership behavior on the business growth through the organizational innovation and managerial practices. Arch. Bus. Res. 2017, 5. [CrossRef]

17. Škarvada, P.; Tománek, P.; Koktavý, P.; Macků, R.; Šicner, J.; Vondra, M.; Dallaeva, D.; Smith, S.; Grmela, L. A variety of microstructural defects in crystalline silicon solar cells. Appl. Surf. Sci. 2014, 312, 50-56. [CrossRef]

18. Bernardoni, P.; Mangherini, G.; Gjestila, M.; Andreoli, A.; Vincenzi, D. Performance Optimization of Luminescent Solar Concentrators under Several Shading Conditions. Energies 2021, 14, 816. [CrossRef]

19. Shakeel, S.R.; Rahman, S.U. Towards the establishment of renewable energy technologies' market: An assessment of public acceptance and use in Pakistan. J. Renew. Sustain. Energy 2018, 10, 045907. [CrossRef]

20. UNDP, U. Being LGBT in Asia: Thailand Country Report; UNDP Asia-Pacific Regional Centre: Bangkok, Thailand, 2014.

21. Rubenstein-Montano, B.; Liebowitz, J.; Buchwalter, J.; McCaw, D.; Newman, B.; Rebeck, K.; Team, T.K. A systems thinking framework for knowledge management. Decis. Support Syst. 2001, 31, 5-16. [CrossRef]

22. Santoro, G.; Vrontis, D.; Thrassou, A.; Dezi, L. The Internet of Things: Building a knowledge management system for open innovation and knowledge management capacity. Technol. Forecast. Soc. Chang. 2018, 136, 347-354. [CrossRef]

23. Nonaka, I.; Hirose, A.; Takeda, Y. 'Meso'-Foundations of Dynamic Capabilities: Team-Level Synthesis and Distributed Leadership as the Source of Dynamic Creativity. Glob. Strategy J. 2016, 6, 168-182. [CrossRef]

24. Barney, J. Firm resources and sustained competitive advantage. J. Manag. 1991, 17, 99-120. [CrossRef]

25. Mahoney, J.T.; Pandian, J.R. The resource-based view within the conversation of strategic management. Strateg. Manag. J. 1992, 13, 363-380. [CrossRef]

26. Naz, S.; Li, C.; Nisar, Q.A.; Rafiq, M. Linking emotional intelligence to knowledge sharing behaviour: Mediating role of job satisfaction and organisational commitment. Middle East J. Manag. 2019, 6, 318-340. [CrossRef]

27. López-Nicolás, C.; Meroño-Cerdán, Á.L. Strategic knowledge management, innovation and performance. Int. J. Inf. Manag. 2011, 31, 502-509. [CrossRef]

28. Cheema, A.; Khwaja, I.; Khan, A. Decentralization in Pakistan: Context, content and causes. In Decentralization and Local Governance in Developing Countries: A Comparative Perspective; Bardhan, P., Mukherjee, D., Eds.; MIT Press: Cambridge, MA, USA, 2005.

29. Ilyas, M.; Rafiq, M. Impact of Corporate Governance on Perceived Organizational Success (Empirical Study on Consumer Banks in Lahore, Pakistan). Int. J. Bus. Soc. Sci. 2012, 3, 178-187.

30. John, M.; Chathukulam, J. Measuring decentralisation: The case of Kerala (India). Public Adm. Dev. Int. J. Manag. Res. Pract. 2003, 23, 347-360.

31. Schroeder, W.; Weinert, R. Managing Decentralization: The Strategy of Institutional Differentiation in German Industrial Relations. Ger. Politics Soc. 1999, 17, 52-73. [CrossRef]

32. Agyemang-Duah, W.; Kafui Gbedoho, E.; Peprah, P.; Arthur, F.; Kweku Sobeng, A.; Okyere, J.; Mengba Dokbila, J. Reducing poverty through fiscal decentralization in Ghana and beyond: A review. Cogent Econ. Financ. 2018, 6, 1476035. [CrossRef]

33. Vengroff, R.; Salem, H.B. Assessing the impact of decentralization on governance: A comparative methodological approach and application to Tunisia. Public Adm. Dev. 1992, 12, 473-492. [CrossRef]

34. Çakın, B. Decentralization as a Conflict-Resolution Mechanism on Kurdish Conflict in Turkey: Panacea or Poison? University of Twente: Enschede, The Netherlands, 2017.

35. Karmaker, C.L.; Ahmed, T.; Ahmed, S.; Ali, S.M.; Moktadir, M.A.; Kabir, G. Improving supply chain sustainability in the context of COVID-19 pandemic in an emerging economy: Exploring drivers using an integrated model. Sustain. Prod. Consum. 2020, 26, 411-427. [CrossRef] [PubMed]

36. Paauwe, J. HRM and performance: Achievements, methodological issues and prospects. J. Manag. Stud. 2009, 46, 129-142. [CrossRef]

37. Penrose, R. The apparent shape of a relativistically moving sphere. In Mathematical Proceedings of the Cambridge Philosophical Society; Cambridge University Press: Cambridge, UK, 1959.

38. Conner, K.R. A historical comparison of resource-based theory and five schools of thought within industrial organization economics: Do we have a new theory of the firm? J. Manag. 1991, 17, 121-154. [CrossRef]

39. Wernerfelt, B. A resource-based view of the firm. Strateg. Manag. J. 1984, 5, 171-180. [CrossRef]

40. Grant, R.M. Toward a knowledge-based theory of the firm. Strateg. Manag. J. 1996, 17, 109-122. [CrossRef]

41. Lee, H.; Choi, B. Knowledge management enablers, processes, and organizational performance: An integrative view and empirical examination. J. Manag. Inf. Syst. 2003, 20, 179-228.

42. Lee, N.; Saunders, J.; Goulding, C. Grounded theory, ethnography and phenomenology. Eur. J. Mark. 2005, 39, $294-308$.

43. Creswell, J.W. Controversies in mixed methods research. Sage Handb. Qual. Res. 2011, 4, 269-284.

44. Warfield, J.N. Developing interconnection matrices in structural modeling. IEEE Trans. Systems Man Cybern. 1974, 81-87. [CrossRef]

45. Sage, A.P. Methodology for Large-Scale Systems; McGraw-Hill: New York, NY, USA, 1977; pp. 165-203.

46. Sadler, G.R.; Lee, H.C.; Lim, R.S.; Fullerton, J. Recruitment of hard-to-reach population subgroups via adaptations of the snowball sampling strategy. Nurs. Health Sci. 2010, 12, 369-374. [CrossRef]

47. Wu, H.; Niu, D. Study on influence factors of electric vehicles charging station location based on ISM and FMICMAC. Sustainability 2017, 9, 484. [CrossRef] 
48. Richard, P.J.; Devinney, T.M.; Yip, G.S.; Johnson, G. Measuring organizational performance: Towards methodological best practice. J. Manag. 2009, 35, 718-804. [CrossRef]

49. Rondinelli, D.; Nellis, J.R.; Cheema, G.S. Decentralization in Developing Countries; World Bank Staff Working Paper, Number 581; The World Bank: Washington, DC, USA, 1983. [CrossRef] 